\title{
Application of Soft Computing Methods to Increase Sustainability in Construction
}

\author{
Silvana V. Petruseva ${ }^{1}$ and Valentina K. Zileska Pancovska ${ }^{2}$ \\ ${ }^{1}$ University "Ss. Cyril and Methodius", Faculty of Civil Engineering, Skopje, Blvd. Partizanski \\ Odredi 24, 1000 Skopje, North Macedonia, silvana@gf.ukim.edu.mk \\ ${ }^{2}$ University "Ss. Cyril and Methodius", Faculty of Civil Engineering, Skopje, Blvd. Partizanski \\ Odredi 24, 1000 Skopje, North Macedonia, valentinazp@gf.ukim.edu.mk
}

\begin{abstract}
In the last three decades the soft computing methods were used by the research community in almost every branch of construction, providing successful and convenient solutions for different problems in civil engineering. This paper presents some of the applications of these methods-especially neural networks (NN) and support vector machine (SVM) - in sustainable construction, i.e. its economic, social and environmental aspects. Soft computing applications were made in the last several years by our research team at the Faculty of Civil Engineering in Skopje, N. Macedonia, in collaboration with other authors from our and other countries. Several predictive models were developed using: general regression neural network (GRNN), support vector machine (SVM) and radial basis function neural network (RBF NN), using predictive modelling software DTREG. Applications of these models cover most of the aspects of sustainability in construction. Models were focused on predicting: road structure construction costs, bidding price in construction, sustainability assessment at early facilities design phase, predicting construction cost and construction time and predicting consumption of energy in buildings. Some of the mentioned developed predictive models are hybrid, composed of process-based and data driven models which contributed very much to the improvement of the accuracy of the predicting. The general conclusion is that the soft computing methods are a useful tool for developing models in the area of all aspects of sustainability and their application can lead to increasing sustainability in construction.
\end{abstract}

Keywords: Sustainable Construction, Soft Computing Methods, Predictive Modelling.

\section{Introduction}

The construction industry creates conditions for the whole development of the country, but it can have some negative impact on the sustainability aspects: environmental, social or economic aspect. In that regard, balancing society's needs with environmental and economical demands, the construction industry should fulfil the present society needs, but with respect to its future needs (Chendo, 2013; Rafandadi et al., 2014).

The implementation of sustainable construction procedures is a slow process, mostly due to the widely spread opinion that they are time, effort and cost more demanding than traditional ones (Dobson et al., 2013). Hence, meeting the sustainable aims has become a construction project participants' challenge and researches' focus worldwide. They have researched different sustainable aspects using various of techniques and methods. Some of them are soft computing methods (SCMs). SCMs are noted as useful for developing models for different sustainable problems in construction (Polat et al., 2014; Ahmad et al., 2014; Arida et al., 2016). Therefore, the aim of this paper is to present a brief review of the authors' research on several construction 
sustainability issues by using SCMs. The models were focused on predicting: sustainability assessment, bidding price, construction time, construction cost and energy consumption of buildings.

Sustainability assessment: Facilities construction is globally noted as having large consequences on sustainability aspects. Thus, in spite of the existence of numerous obstacles, balancing sustainable issues and their incorporating in facilities construction and maintaining is a challenge for all participants in the construction projects (Aksorn and Charoenngam, 2015). Therefore, the early design phase is seen as a phase with high impact on facilities sustainability due to its providing drawings and specifications for the facility in accordance with the clients' wishes and needs (Crawford, 2013). Facility design which integrates the sustainability issues provides benefits for the project participants, the facility users and the whole society (Adeyeye et al., 2013). But that is a complex process which puts designers under pressure. Therefore, construction project managers can support the inclusion of sustainability aspects in the facility's design which will lead to increasing the money value of the facility, while providing satisfied customers and construction of eco-friendly facility.

Bidding price: Construction companies usually acquire their work by winning a tender. Hence, choosing the bidding price that will win the tender is of particular interest for each construction company. But the decision what price to bid is a responsible, time and effortconsuming process which is influenced by a set of factors (Watt et al., 2009). Therefore, having a model for predicting the price in order to win the bid is useful and it facilitates the decision making process.

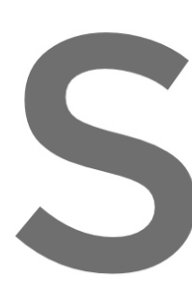

Construction tim construction. Hence, contracted time and regarding construction relation, their influendin
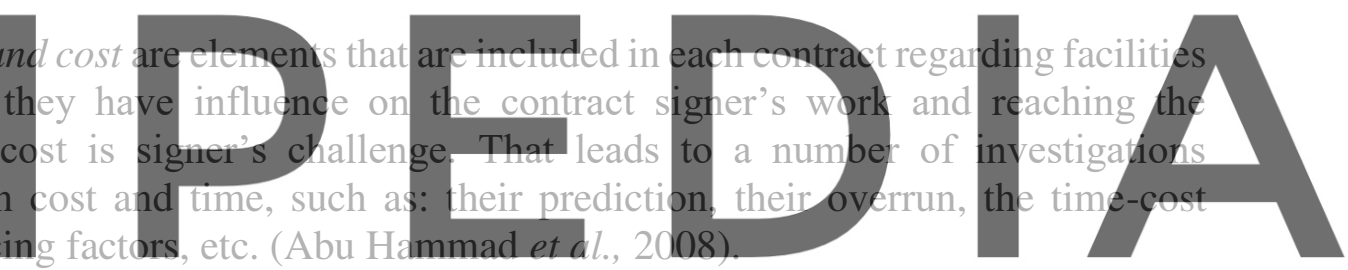

Energy consumption of buildings has an impact, not only on the comfort, costs and other

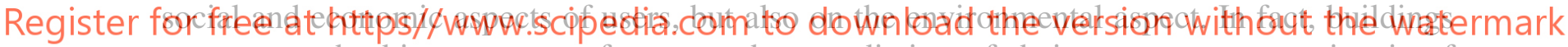
are among the biggest users of energy, thus prediction of their energy consumption is of particular interest. During the stage of selecting the optimal design of the new building or old building reconstruction/renovation, numerous measures/solutions can be used for reducing the building's energy consumption. Some of them are: system with heat pump from ground source (Michopoulos et al., 2016); renewable energy systems usage and their combination or combination of systems for heating, power and cooling; system installation for energy management, etc. (Farhat et al., 2014; Rasool et al., 2015; Kialashaki, 2018). Thus, of particular interest is to have models for energy consumption forecasting.

\section{Literature Review}

Sustainability outcomes and environment protection are in a significant positive relation (Smith and Rootman, 2013), so for owners the sustainability has impact on their portfolio (WarrenMyers, 2012). Rafindadi et al., (2014) stated that there is no significant difference among project stakeholders on sustainable projects risks, so for Babawale and Oyalowo (2011) the real estate valuers should have more knowledge about sustainability aspects of properties in order to effectively assess their value. For Dobson et al., (2013) there is perception that capital costs 
for sustainability are high, which can be an obstacle for the construction.

Bidding price in construction - There are different categories of bidding-price models, such as: models that are directed towards maximization of the expected; models based on systems for decision support; models based on artificial intelligence, etc. (Polat et al., 2014). For example: a bidding model that uses generic software for probability estimating of the success is presented by Kitchenham et al., (2005).

Construction time and cost relation and their overruns are researched worldwide. Zhang and $\mathrm{Ng}$ (2012) solved time-cost optimization problems using evolutionary-based optimization algorithm. Similarly, Afshar and Fathi (2009) used Fuzzy-sets theory for accounting the uncertainness in each activity direct cost, in order to determine the financing cost and required credit. They developed a model for searching the solutions that are non-dominated for the construction objectives: total time, financing cost and required credit.

Energy consumption of buildings is among issues that are highly researched, from different aspects and using different methods and techniques. Widely used are: traditional numerical methods, statistical methods and intelligent methods. Promised results were given by: Ekici and Aksoy (2009) using backpropagation ANN; Holcomb et al., (2009) with support vector regression, ANN and multilinear regression; Ahmad et al., (2014) with support vector machine and ANN coneluding that hybridization of these methods is suitable for more accurate prediction; Arida et al., (2016) using ANN, particular non-linear auto-regression ANN; Amber et al., (2017) using the Multiple Regression technique; Li et al., (2017) using extreme deep

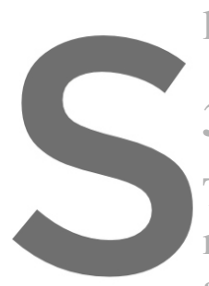
learning approach, etc

\section{Methods}

There are generally two types of methods for a modern soft computing methods. The hard analytical model of the process that should be inc
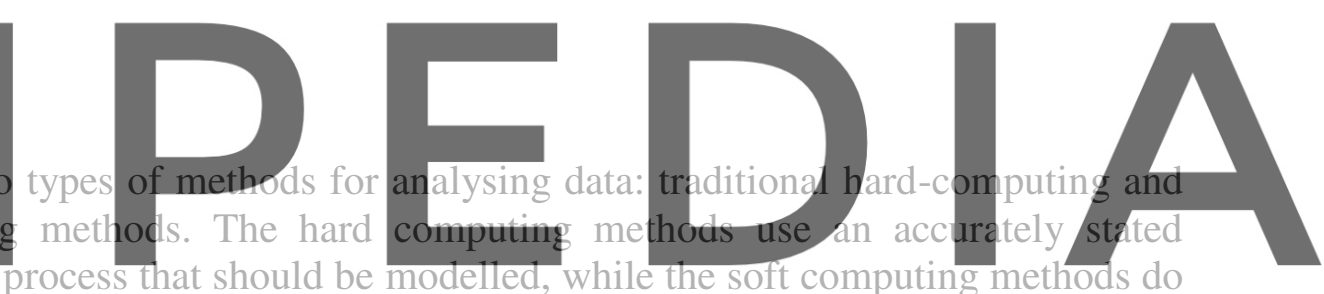
not need analytical model of the process. The soft computing methods.have been developed as

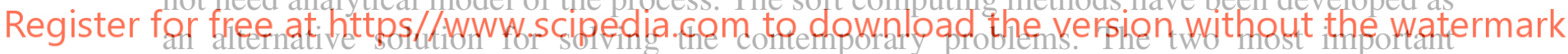

constituents of soft computing are learning from experimental data (neural networks and support vector machine) and fuzzy logic methods, but in recent years there are aiso other: probabilistic reasoning, genetic algorithms, chaos theories, fractals (Kecman, 2001). There are many different types of NNs developed for solving different problems, some of them being: GRNN, RBF NN, polynomial NN, probabilistic NN, multilayer perceptron (MLP), cascade correlation NN. In our research we have used only the first two.

\subsection{Data-Driven Soft Computing Methods}

Soft computing methods try to transfer the human knowledge into mathematical, analytical models by finding methods for learning from experimental data.

NNs and SVMs are mathematical computing models that implement the idea of learning from experimental data, and FL systems implement structured human knowledge into effective computing algorithms (Kecman, 2001). 


\subsubsection{Artificial neural networks (ANNs)}

NNs implement the functioning of the human neurons. The three most important aspects of the NNs are: implementation of biological neural networks, the concept of parallel distributing processing and the concept of learning and self-organizing (Haykin, 2005). NNs can approximate multivariable nonlinear functions, identifying the interactions between input and output data easily, minimizing some error function which expresses the difference between actual output values and the predicted values by the NN. In our research most often used NNs were: GRNN and RBF NN.

Radial basis function neural network ( $R B F N N$ ) is a 3 layered feed forward network (Figure 1 (Sherrod, 2013b)). The values from the input neurons are fed to the neurons from the next hidden layer, which has mutable number of neurons determined by the algorithm for the training process. RBF NN can have one or several outputs, depending on the task which is solved; if it is used for forecasting then RBF NN has only one output, but if it is used for classification, then it may have several outputs, equal to the number of categories of the target variable.

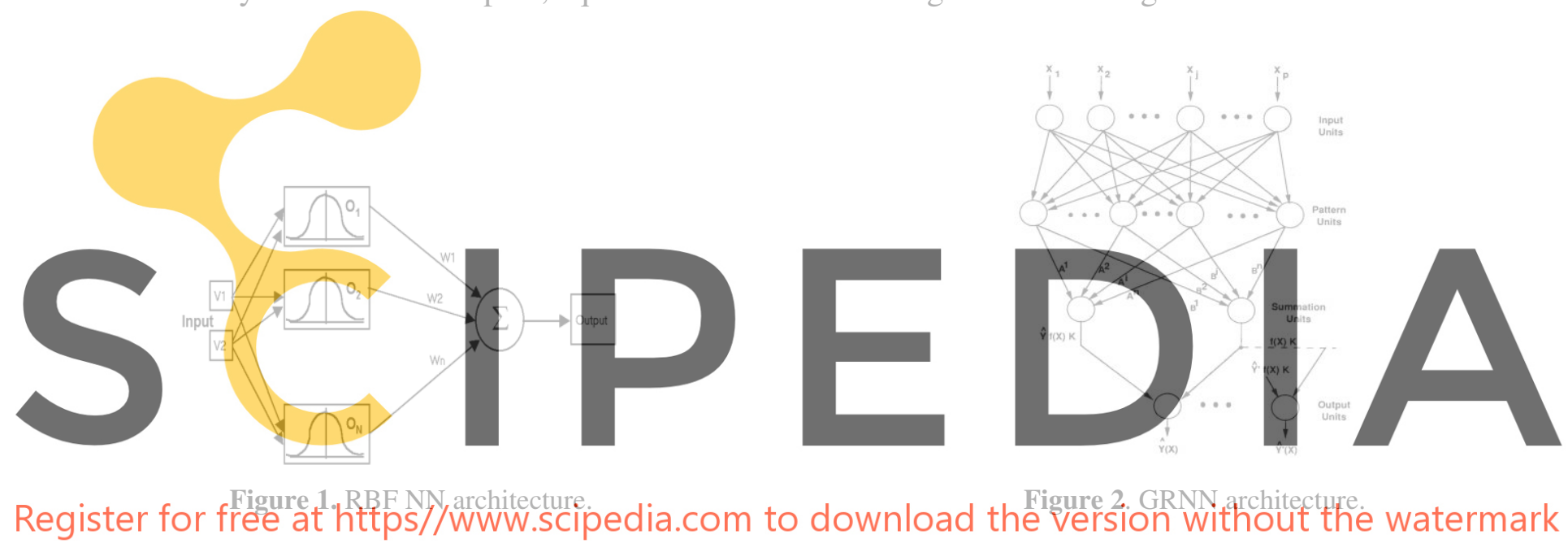

General regression neural network (GRNN) is most often used NN in our research. This NN is in most of the cases very accurate and is used for forecasting, control problems, mapping (Specht, 1991). The most attractive characteristic of GRNN is its ability to converge to the optimal solution very quickly, requiring only several samples. GRNN has 4 layers (Figure 2) (Sherrod, 2013b).

\subsubsection{Support vector machine (SVM)}

SVM models have been developed to solve the contemporary problems that have appeared with the standard classical statistical modelling. SVMs can successfully work with standard contemporary multidimensional data sets and also with small training data sets (Kecman, 2001). SVMs have similar architecture as classical NNs. In fact, a two - layer feed forward NN is equivalent to a SVM model which uses sigmoid kernel function. 


\subsection{Bromilow Process-Based Model and Hybrid Modelling}

The soft computing methods that were described above are data-driven methods, and they do not use any knowledge about the process which should be modelled in a form of some mathematical formula. Process-based methods describe the process by some mathematical formulae. The hybrid modelling is a relatively new field of investigation and very promising results have been reported.

The process-based model used in our research was the well-known Bromilow "time-cost" model which gives the relation between construction time and construction cost. This model is given by the equation (1):

$$
\boldsymbol{T}=\boldsymbol{a} \boldsymbol{C}^{\boldsymbol{b}}
$$

$\mathrm{T}$ is a construction time, $\mathrm{C}$ is a construction cost (price), $a$ is a model parameter which expresses the average time needed for construction of a monetary value, and $b$ is parameter which expresses the dependence of the time on cost change (Bromilow, 1969).

\section{Results and Discussions}

Using the methods described above, in the last several years predictive models applied for solving different problems in civil engineering have been developed by the research team from our country and also with collaboration with authors from other countries. The software used for developing the models was predictive modelling software DTREG (Sherrod, 2013a, 2013b). The developed models construction time, cons data for developing the models model. The most used method for validation The accuracy of the models has been estima absolute percentage error), and the coefficient of determination $\mathrm{R}^{2}$ which measures the global Register för ofrele atoldtt.ps//www.scipedia.com to download the version without the watermark Sustainability assessment: 112 project managers from construction firms in R. Macedonia were participants in an anonymous survey, whose goal was to determine their opinion about the factors that mostly affect the sustainability assessment of the facilities' preliminary design. The questionnaire developed by the authors consisted of 72 questions, seen as factors that influence the sustainability of the facilities preliminary design. 27 of them were chosen as most representative for building the model. The participants were asked to answer the questions on a 6 point Likert scale (from 1 - unimportant, to 6 - extremely important). The questions were considered as predictors for the model. One of them was considered as target variable - the question: sustainability assessment of the preliminary design. GRNN from DTREG predictive modelling software was used for modelling. DTREG also computes the most important factors that impact the target variable, and the 6 most influential of them reported by DTREG were: 1 ) work experience, 2) work on several outline design proposals, 3) resolving issues between stakeholders, 4) prioritization of participants in the design phase, 5) procurement management and 6) defining project program and goals. The conclusion from this modelling is the finding that the project managers assessed the social aspects more influencing sustainability and economic and environmental issues less influential. The accuracy of the model was: MAPE= $2.6 \%$ and the coefficient of determination was $\mathrm{R}^{2}=0.84$ (Zileska et al., 2017). 
Bidding price: A model for forecasting bidding price was developed using SVM method for prediction. Data from 26 tenders were used for modelling out of 54 tenders that were collected from construction firms. Two variables were used as predictors (time for preparation and the price offered) and the target variable was price obtained. The accuracy of the model was with MAPE $2.5 \%$, and $\mathrm{R}^{2}=89.8 \%$, (Petruseva et al., 2016).

Construction time: Several hybrid models were developed for predicting time of construction using Bromilow time-cost model (BTC model) as process-based model. One of them was hybrid, composed of BTC model and GRNN model and it was modelled with data for 116 different types of structures: road structures, petrol stations, bridges, education facilities, business buildings, and other. The data was about purpose of the structure, year of construction, region of location, contracted time and cost and also realized time and cost. Target variable was real time of construction, and as predictors were chosen: purpose of the structure, real and contracted cost and contracted time. The accuracy of the model was: MAPE $=3.3 \%$ and $\mathrm{R}^{2}=93.2 \%$, using purpose of construction (as string variable), and contracted time, contracted cost and real cost of construction as predictors, and target variable was real time of construction. The input values of real and contracted time of construction and real and contracted cost of construction were not their actual values, but logarithm of their values, because of the application of the BTC model (eq. 1). This equation was applied for the relation of the real time and real cost of construction, and also for the contracted time and cost, and these two equations were logaritmized and summarized and the obtained equation was a relationship between their logarithmic values. We shall stress here the importance of the hybrid model which drastically improved the accuracy model, the accuracy df (Petruseva, Car-Pusic Construction cost: One of the developed madels for predict model, composed of RBF NN and BTC model with accuracy:
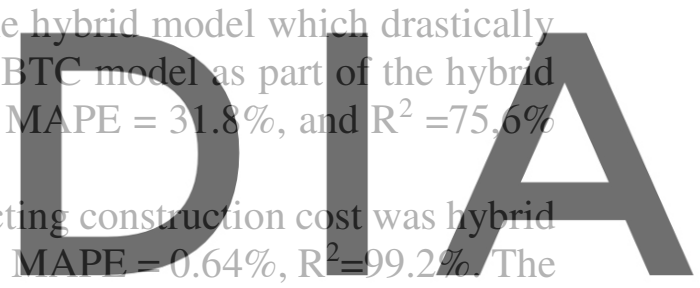

data were for 65 objects. Target variable was the real cost of construction, and predictors:

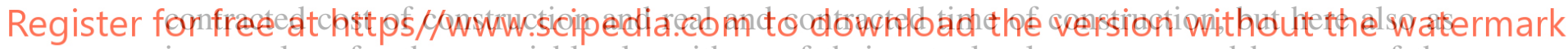
input values for these variables logarithms of their actual values were used because of the application of the BTC model. Without BTC model as part of the hybrid model, using only RBF NN, the accuracy of the model was: MAPE around $54 \%$ and $\mathrm{R}^{2}$ around $44 \%$ (Zileska and Petruseva, 2017).

Energy consumption of buildings: The model developed for predicting building energy consumptions used data for real energy consumption for 55 residential buildings in $\mathrm{R}$. Macedonia, constructed/reconstructed from 2013 to 2018. The accuracy of the model, using GRNN was: $\mathrm{MAPE}=3.12 \%$ and $\mathrm{R}^{2}=91.7 \%$. The target variable was building energy consumption $\mathrm{Q}\left[\mathrm{kwh} / \mathrm{m}^{2} / \mathrm{year}\right]$, and from all available data, 10 were chosen as most representative predictors, which were related to: 1 ) thermal transmittances (in $\mathrm{W} / \mathrm{m}^{2}$ ) of: walls, windows, floors, roofs, and also: 2 ) their corresponding geometries and areas (in $\mathrm{m}^{2}$ ) - areas of the floors, walls and roofs (Zileska, Petruseva and Samardzioska, 2018).

\section{Conclusions}

Sustainability aspects are complex and inter-connected, so their researching and incorporating in construction is an effortful process. Furthermore, there are many sustainability influencing 
factors, so it's useful to have prediction models for sustainable aspects. Recently, the most popular soft computing methods used for predictive modelling have been SVMs and NNs

(GRNN, RBF NN, MLP, polynomial NN, cascade correlation NN, probabilistic NN). In the last several years we have developed several predictive models using mostly GRNN, SVM, RBF NN, and several hybrid models composed of data-driven and process-based model. The developed models gave a satisfied accuracy in prediction of: manager's assessment of the sustainability in early design phase for the facility, building energy usage, bidding price, construction time, construction cost, etc.

The models presented in this paper showed that the usage of SCMs facilitates the decision making process and leads to increasing the sustainability in construction.

\section{ORCID}

Silvana Petruseva: http://orcid.org/0000-0002-3752-513X

Valentina Zileska Pancovska: https://orcid.org/0000-0001-7620-4040

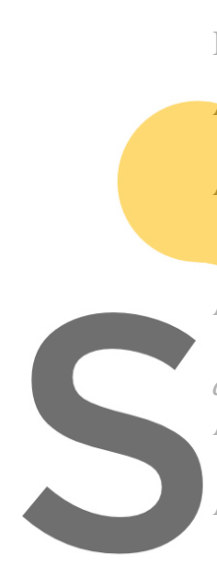

References

Adeyeye, K., Piroozfar, P., Rosenkind, M., Winstanley, G. and Pegg, I. (2013). The impact of design decisions on post occupancy processes in school buildings. Facilities, 31(5/6), 255-278.

Afshar, A. and Fathi, H. (2009). Fuzzy multi-objective optimization of finance-based scheduling for construction projects with uncertainties in cost. Engineering Optimization, 41(11), 1063-1080, doi: 10.1080/03052150902943004

Ahmad, S.A., Hassan, Y.M., Abdullah, P.M. Rahman, review on applications of and Sustainable Energy Revi

Aksorn, P. and Charoenn water resource, water Amber, K.P., Aslàm, M.Y. S.K. (2017). Énergy co of ANN and
am, C. (2015)
upply, and local
., Mahmodod
consumption h, P.M. Rahman,
102-109. https://d
15). Sustainability
ocal market proje
d A., Kousar, A.,
forecasting for

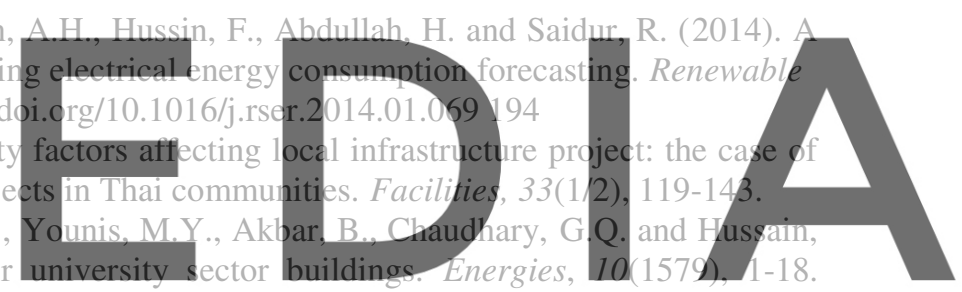
doi:10.3390/en10101579

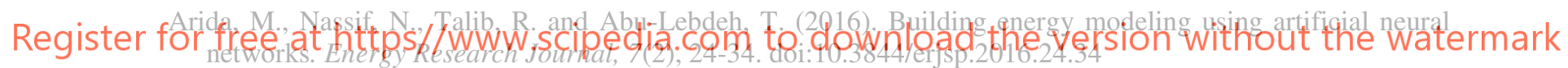

Babawale, G. K. and Oyalowo, B. A. (2011). Incorporating sustainability into real estate valuation: the perception of Nigerian valuers. Journal of Sustainable Development, 4(4), 236.

Bromilow, F.J. (1969). Contract time performance expectations and reality. Building forum 1: $70-80$.

Chendo, N.A. (2013). Managers' perception of environmental sustainability in small and medium scale enterprises (SMEs): Implication for competitive marketing advantages for sachet water manufacturers in Anambra State, Nigeria. European Journal of Business and Management, 5(7), 186-195.

Crawford, L. (2013). Sustainability Integration for Effective Project Management - Chapter 14: Leading sustainability through projects. In Silvius, A.J.G. and Tharp, J. (Eds), IGI Global Publishing, Hershey, PA, 235-244.

Dobson, D. W., Sourani, A., Sertyesilisik, B. and Tunstall, A. (2013). Sustainable construction: analysis of its costs and benefits. American Journal of Civil Engineering and Architecture, 1(2), 32-38.

Ekici, B.B. and Aksoy, T.U. (2009). Prediction of building energy consumption by using artificial neural networks. Advances in Engineering Software. 40(5). 356-362. https://doi.org/10.1016/j.advengsoft.2008.05.003

Farhat, R., Ghaddar, K.N. and Ghali. K. (2014). Investing in PV systems utilizing savings from building envelop replacement by sustainable local material: a case study in Lebanese inland region. International Journal of Energy Economics and Policy. 4(4), 554-567.

Hammad, A.A.A., Alhaj Ali, M.S., Ghaleb, S.J. and Bashir, A. (2008). Prediction model for construction cost and duration in Jordan. Jordan Journal of Civil Engineering, 2, 250-266.

Haykin, S. (2005). Neural networks: a comprehensive foundation, 2nd ed., Pearson Education Inc., Canada. 
Holcomb, D., Li, W. and Seshia, A.S. (2009). Algorithms for green buildings: Learning-based techniques for energy prediction and fault diagnosis. Electrical Engineering and Computer Sciences. University of California at Berkeley Technical Report No. UCB/EECS-2009-138 University of California at Berkeley. http://www.eecs.berkeley.edu/Pubs/TechRpts/2009/EECS-2009-138.html

Kecman, V. (2001). Learning and Soft Computing: support vector machines, neural networks and fuzzy logic models. A Bradford Book. The MIT Press, Cambridge, Massachusetts, London, England.

Kialashaki, Y. (2018). A linear programming optimization model for optimal operation strategy design and sizing of the CCHP systems. Energy Efficiency, 11(1), 225-238.

Kitchenham, B.A., Pickard, L., Linkman, S. and Jones, P. (2005). A framework for evaluating a software bidding model. Information and Software Technology, 47(11), 747-760.

Li, C., Ding, Z., Zhao, D., Yi, J. and Zhang, G. (2017). Building energy consumption prediction: an extreme deep learning approach. Energies. 10(1525), 1-20. doi:10.3390/en10101525

Michopoulos, A., Voulgari, V., Tsikaloudaki, A. and Zachariadis, Th. (2016). Evaluation of ground source heat pump systems for residential buildings in warm Mediterranean regions: the example of Cyprus. Energy Efficiency, 9(6), 1421-1436.

Petruseva, S., Sherrod, P., Zileska Pancovska, V. and Petrovski, A. (2016). Predicting Bidding Price in Construction using Support Vector Machine. Tem Journal, 5(2), 143-151.

Petruseva, S., Zileska-Pancovska, V. and Car-Pusic, D. (2019). Implementation of process-based and data-driven models for early prediction of construction time. Advances in Civil Engineering (HINDAWI), Article ID 7405863, 12 pages, doi: 10.1155/2019/7405863

Polat, G., Bingol, B.N. and Uysalo, E. (2014). Modeling bid/no bid decision using adaptive neuro fuzzy inference system (ANFIS): a case study. Construction Research Congress 2014, American Society of Civil Engineers, 1083-1092. https://ascelibrary.org/doi/abs/10.1061/9780784413517.111, (access7 Aug. 2019).

Rafindadi, A.D.U., Mikić, M., Kovačić, I. and Cekić, Z. (2014). Global perception of sustainable construction project risks. 27th IPMA World Congress, Procedia-Social and Behavioural Sciences, 119, 456-465.

Rasool, Z., Tariq, W., Othman, L.M. and Jasni, J. (2015). What building management system can o

power wastage both social an The SIJ Transactions o

Smith, E.E. and Rootman, organizations. Busines

Sherrod, P. (2013a). Predicti

Sherrod, P. (2013b). Predicti
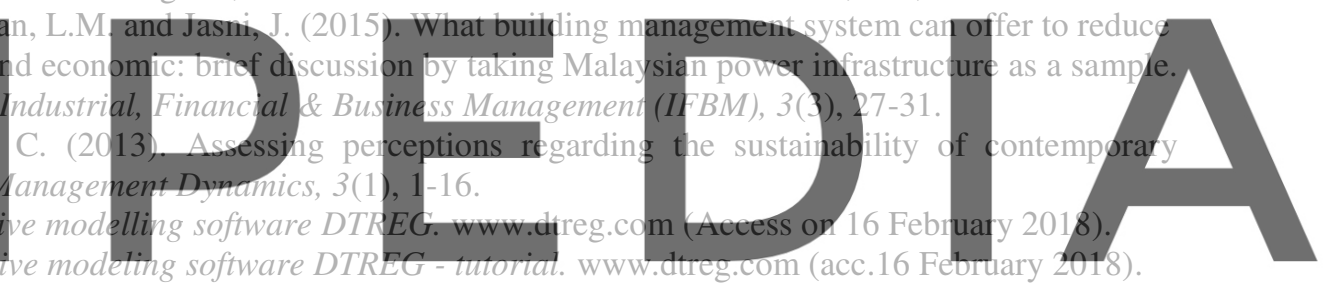

Specht, D.F.(1991). A general regression neural network. IEEE Transactions on neural networks, 2(6), 568 - 576.

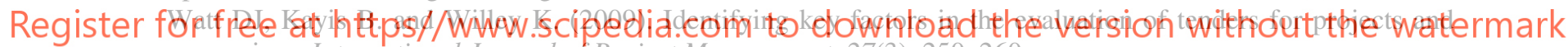
services. International Journal of Project Management, 27(3), 250-260.

Warren-Myers, G. (2012). Sustainable management of real estate: is it really sustainability? The Journal of Sustainable Real Estate, 4(1), 177-197.

Zhang, Y. and Ng, T.S. (2012). An ant colony system based decision support system for construction time-cost optimization. Journal of Civil Engineering and Management, 18(4), 580-589.

Zileska Pancovska, V., Petruseva, S. and Petrovski, A. (2017). Predicting Sustainability assessment at early facilities design phase. Facilities, 35( 5/6), 335-355.

Zileska-Pancovka, V. and Petruseva, S. (2017). Estimation of facilities construction cost using radial basis function neural network. In Proceedings of CIRRE-2nd Conference of Interdisciplinary Research on Real Estate, Cartagena, Spain, 88-98.

Zileska Pancovska, V., Petruseva, S. and Samardzioska,T. (2018). Building's energy consumption forecasting a model based on general regression neural network. In Book of Proceedings of the 3th Conference of Interdisciplinary Research on Real Estate (CIRRE 2018), Groningen, Netherlands, 186-196. 